\title{
ASPECTOS BIOLÓGICOS E MORFOLÓGICOS DE Mimallo amilia (LEPIDOPTERA: MIMALLONIDAE) EM FOLHAS DE Eucalyptus urophylla ${ }^{1}$
}

\begin{abstract}
Teresinha Vinha Zanuncio ${ }^{2}$, José Cola Zanuncio ${ }^{3}$, José Salazar Zanuncio Junior ${ }^{3}$, Germi Porto Santos ${ }^{4}$,
\end{abstract} Maria do Carmo Queiroz Fialho ${ }^{2}$ e Aline Sales Bernardino ${ }^{3}$

\begin{abstract}
RESUMO - Abiologia de Mimallo amilia Cramer (Lepidoptera: Mimallonidae) foi estudada em folhas de Eucalyptus urophylla em laboratório a $25 \pm 2{ }^{\circ} \mathrm{C}, 60 \pm 10 \%$ de umidade relativa e fotoperíodo de 12 horas de luz e 12 horas de escuro. Essa espécie teve duração da fase larval de 34,88 dias e cinco estádios larvais. Houve mortalidade de lagartas no primeiro, terceiro e quarto estádios com 5,00; 7,89; e 14,28\%, respectivamente. Os períodos de pré-pupa e de pupa foram de 4,33 $\pm 0,33$ e 3,90 $\pm 0,23$ e de 18,78 $\pm 0,69$ e 18,82 $\pm 0,41$ dias para machos e fêmeas, respectivamente. Cada fêmea de $M$. amilia depositou 4,86 $\pm 0,48$ posturas com 19,84 $\pm 1,76$ ovos por postura. O período de incubação dos ovos foi de 8,60 $\pm 0,24$ dias, com viabilidade de $88,63 \%$. A longevidade de adultos foi de 5,66 0,61 e 9,22 $\pm 0,79$ dias, com envergadura das asas de 42,70 $\pm 0,32$ e 49,70 $\pm 0,17$ $\mathrm{mm}$ para machos e fêmeas, respectivamente, e razão sexual de 0,56 . As lagartas dessa espécie apresentaram tamanho de $0,90 \pm 0,01 \mathrm{~mm}$ no primeiro estádio a 4,40 $\pm 1,42 \mathrm{~mm}$ no último.
\end{abstract}

Palavras-chave: Desfolhadores, eucalipto e Psidium guajava.

\section{BIOLOGICAL AND MORPHOLOGICAL ASPECTS OF Mimallo amilia (LEPIDOPTERA: MIMALLONIDAE) IN Eucalyptus urophylla LEAVES}

\begin{abstract}
The biology of Mimallo amilia Cramer (Lepidoptera: Mimallonidae) was studied on Eucalyptus urophylla leaves in laboratory conditions $\left(25 \pm 2^{\circ} \mathrm{C}, 60 \pm 10 \%\right.$ relative humidity and $12 \mathrm{~L}: 12 \mathrm{D}$ photoperiod). This species showed 33.88 day for the larval stage with five larval instars. Larval mortality occurred during first, third and fourth instars with 5.00, 7.89 and 14.28\%, respectively. Pre-pupa and pupa stages lasted $4.33 \pm 0.33$ and $3.90 \pm 0.23$, and $18.78 \pm 0.69$ and $18.82 \pm 0.41$ days for males and females, respectively. Each female laid $4.86 \pm 0.48$ egg masses with $19.84 \pm 1.76$ eg gs per egg mass. Incubation period lasted $8.60 \pm 0.24$ days with $88.63 \%$. egg viability. Adult longevity was $5.66 \pm 0.61$ and $9.22 \pm 0.79$ days with adult wingspan of $42.70 \pm 0.32$ and $49.70 \pm 0.17 \mathrm{~mm}$ for males and females, respectively, with 0.56 sex ratio. Length of this species' caterpillars was $0.90 \pm 0.01 \mathrm{~mm}$ at the first instar and $4.40 \pm 1.42 \mathrm{~mm}$ at the last instar.
\end{abstract}

Key words: Caterpillars, eucalypt and Psidium guajava.

\footnotetext{
${ }^{1}$ Recebido em 29.03.2004 e aceito para publicação em 25.11.2004.

${ }^{2}$ Bolsista de Pós-Doutorado do CNPq, vinculada ao Departamento de Biologia Animal da UFV. E-mail: <tvzanuncio@ufv.br>. ${ }^{3}$ Departamento de Biologia Animal da Universidade Federal de Viçosa, 36570-000 Viçosa, Minas Gerais. E-mail:<zanuncio@ ufv.br>.

${ }^{4}$ Empresa de Pesquisa Agropecuária de Minas Gerais - Centro Tecnológico da Zona da Mata, Vila Gianetti, 46/47. Cep: 36570-000 Viçosa, MG.
} 


\section{INTRODUÇÃO}

No Brasil, os reflorestamentos são compostos, principalmente, por espécies do gênero Eucalyptus (Myrtaceae) em monoculturas criando condições favoráveis para a ocorrência de insetos-praga, como formigas cortadeiras e lepidópteros desfolhadores. Neste último grupo, estão incluídos Thyrinteina arnobia (Lepidoptera: Geometridae), cuja ocorrência e inimigos naturais foram relatados (BERTI FILHO, 1974), Sarsina violascens (Herrich-Schaffer) (Lepidoptera: Lymantriidae) em Eucalyptus grandis, em Caetanópolis, Minas Gerais (ZANUNCIO e LIMA, 1975) e Psorocampa denticulata Schaus (Lepidoptera: Notodontidae) em E. grandis, em Curvelo, Minas Gerais (SANTOS et al.,1982), com danos severos em povoamentos de eucalipto.

Mimallo amilia Cramer (Lepidoptera: Mimallonidae) foi relatada alimentando-se de plantas da família Myrtaceae como Myrciaria dubia, conhecida como camucamuzeiro, que é explorado na região amazônica por apresentar alto teor de ácido ascórbico em seus frutos e utilizada na agroindústria e indústria farmacêutica de países como Japão, França e Estados Unidos (RIBEIRO et al., 2002). Além disso, esse lepidóptero foi relatado como praga secundária de Eucalyptus urophylla em Três Marias, Minas Gerais (PEREIRA et al., 2001; ZANUNCIO et al., 1994a), e o Departamento de Agricultura dos Estados Unidos incluiu essa espécie na categoria 1, como uma das pragas de eucalipto sem ocorrência nesse país (KLIEJUNAS et al., 2001). Isso mostra a importância de se conhecer a biologia de M. amilia visando evitar surtos populacionais desse lepidóptero em plantios de eucalipto, pois a presença de ovos ou mesmo partes desse inseto poderá impedir a exportação de material florestal. A ocorrência, quantificação e catalogação de lepidópteros associados aos plantios de eucalipto foram feitas em diversas regiões do Brasil (ZANUNCIO et al., 1994a). Além disso, tem-se estudado a biologia desses insetos alimentando-se de eucalipto (ZANUNCIO et al., 1990, 1992a, 1994b, 1997, 1998; SANTOS et al., 1998). Por isso, é necessário estudar a biologia e a morfologia, além do comportamento das fases larval e adulta de espécies-praga como $M$. amilia para a correta identificação e avaliação do potencial de dano de espécies desse grupo em surtos nos plantios de eucalipto.

\section{MATERIAL E MÉTODOS}

Foram coletadas lagartas, de vários estádios, de M. amilia em povoamentos de eucalipto nos municípios

R. Árvore, Viçosa-MG, v.29, n.2, p.321-326, 2005 de Montes Claros, Minas Gerais, e Monte Dourado, Pará; e em goiabeira (Psidium guajava), no município de Viçosa, Minas Gerais. Lagartas das duas primeiras regiões foram confinadas em gaiolas de madeira com tela de náilon e tampa de vidro, com $30 \mathrm{~cm}$ de altura, $30 \mathrm{~cm}$ de largura e $30 \mathrm{~cm}$ de profundidade, em laboratório a $25 \pm 2{ }^{\circ} \mathrm{C}, 60 \pm 10 \%$ UR e fotoperíodo de 12 horas, alimentadas com folhas de E. urophylla até a fase adulta.

Após a emergência, 10 casais de $M$. amilia foram individualizados em gaiolas de madeira $(21 \times 21 \times 21$ $\mathrm{cm})$ com tela de náilon e tampa de vidro. Foram colocados galhos de eucalipto no interior dessas gaiolas como substrato para oviposição e um chumaço de algodão embebido em solução de mel $10 \%$.

As posturas de $M$. amilia foram separadas em placas de Petri de 9,0 cm de diâmetro por $1,5 \mathrm{~cm} \mathrm{de}$ altura. Após a eclosão, 40 lagartas foram individualizadas em potes plásticos, opacos, de $500 \mathrm{~mL}$ e alimentadas, diariamente, com duas folhas de eucalipto, com os pecíolos envoltos por um chumaço de algodão embebido em água.

A descrição de lagartas e de adultos de $M$. amilia foi feita com base em exemplares vivos, sendo observados a duração de cada estádio; a largura da cápsula cefálica; o comprimento das lagartas; a mortalidade; os períodos de pré-pupa e pupa; a razão sexual; a longevidade dos adultos; os períodos de pré-oviposição e incubação dos ovos; o número de posturas e de ovos por postura; e a viabilidade dos ovos.

A cápsula cefálica de lagartas de $M$. amilia, nos dois primeiros estádios, foi medida com um micrômetro ocular com 0,05 mm de precisão, adaptado a uma lupa binocular, enquanto nos demais foi usada uma régua milimetrada. Arazão de crescimento foi obtida dividindose o tamanho da cápsula cefálica ou o comprimento do corpo, em cada estádio, pelo tamanho ou comprimento do estádio anterior.

Adultos de M. amilia foram depositados no Museu de Entomologia da Universidade Federal de Viçosa, em Viçosa, Minas Gerais.

\section{RESULTADOS E DISCUSSÃO}

\subsection{Caracterização de ovos e de posturas}

Fêmeas de $M$. amilia apresentaram período de pré-oviposição de 3,20 $\pm 0,41$ dias, $4,86 \pm 0,48$ posturas 
e 19,84 $\pm 1,76$ ovos por postura. O número de óvulos retidos no abdome foi de $36,62 \pm 7,73$ por fêmea. Ovos de $M$. amilia foram colocados, em grupos ou isoladas, no fundo e na tela das gaiolas e, também, nas folhas de eucalipto, indicando que eles devem ser procurados em folhas dessa planta no campo. A longevidade de machos e fêmeas de $M$. amilia foi de 5,66 + 0,61 e 9,22 $\pm 0,79$ dias, respectivamente, com razão sexual de 0,56 .

Ovos de M. amilia apresentam coloração amareloclara brilhante, com coloração roxa próximo à eclosão. São de forma oval, com pequenos nódulos no sentido do comprimento, com 2,82 $\pm 0,007 \mathrm{~mm}$ de comprimento e 1,21 $\pm 0,003 \mathrm{~mm}$ de largura. O período de incubação dos ovos foi de 8,6 $\pm 0,24$ dias e a viabilidade, de 88,63\%. Ovos dessa espécie são grandes comparados aos de outros desfolhadores de eucalipto, como Thyrinteina leucoceraea Rindge (Lepidoptera: Geometridae) (ZANUNCIO et al., 1997), P. denticulata (SANTOS et al., 1982) e Oxydia vesulia (Cramer) (Lepidoptera: Geometridae) (SANTOS et al., 1986), mas sua forma oval é semelhante à de muitas espécies desse grupo.

\subsection{Fase Larval}

Lagartas de $M$. amilia confeccionam um abrigo formado por folhas e fezes unidas por uma teia de coloração bege, onde as lagartas passam a maior parte do tempo. $\mathrm{O}$ abrigo do último estádio é mais resistente e mais fechado, como nas fases de pré-pupa e pupa (Figura 1A). Por isso, a lagarta dessa espécie não é, normalmente, visível no campo, por sair do abrigo apenas para se alimentar. Esse comportamento foi relatado, também, para esse lepidóptero em plantas de $M$. dubia (Myrtaceae) (RIBEIRO et al., 2002).

Mimallo amilia apresentou cinco estádios com duração da fase larval de 34,88 dias e razão de crescimento da cápsula cefálica em torno de 1,5 (Quadro 1), indicando crescimento linear durante a fase larval desse inseto. Isso difere da razão de crescimento acima de 1,6 nos três primeiros e menor que 1,3 nos últimos estádios de T. leucoceraea (ZANUNCIO et al., 1997) e Stenalcidia grosica Schaus (SANTOS et al., 1998) com E. urophylla.

A lagarta de primeiro estádio de $M$. amilia apresenta cabeça marrom-avermelhada com cerdas brancas; corpo dividido em 12 segmentos (três torácicos e nove abdominais), com quatro pares de pseudopatas, do terceiro ao sexto segmento abdominais e um par anal. No dorso do primeiro segmento torácico, há uma placa preta brilhante, em forma de colar, com duas fileiras de cerdas brancas até o ventre. O corpo é marrom, com pintas pretas, envoltas por um círculo de coloração mais clara que o restante do corpo. De cada pinta preta sai uma cerda branca, exceto nos segundo e terceiro segmentos torácicos e na fileira de pintas abaixo dos espiráculos, que apresentam duas cerdas por pinta. $\mathrm{O}$ dorso exibe duas pintas nos segundo e terceiro segmentos torácicos e quatro do primeiro ao nono segmento abdominais, dispostas em pares, duas na frente e duas atrás, e o segmento anal apresenta duas manchas pretas. Os espiráculos circulares são de coloração preta e pouco nítidos e estão presentes no primeiro segmento torácico e do primeiro ao nono segmento abdominal. A duração desse estádio foi de 4,82 $\pm 0,06$ dias, com as lagartas apresentando comprimento de 6,49 $\pm 0,06 \mathrm{~mm}$ (Quadro 1). As lagartas de $M$. amilia são grandes, mesmo no primeiro estádio, o que explica seu comportamento de perfurar a folha, como $P$. denticulata (SANTOS et al., 1982), ao contrário de outros desfolhadores de eucalipto que, apenas, raspam-na (ZANUNCIO et al., 1990, 1992ab, 1994b; SANTOS et al., 1998). Isso indica que esta espécie possui alto potencial de dano desde os primeiros estádios, por ter lagartas de grande porte e poder apresentar consumo foliar elevado.

As lagartas de segundo estádio de M. amilia distinguem-se daquelas do primeiro por apresentarem cabeça preta, com cerdas brancas e corpo preto, com pintas pretas em plano mais elevado que o tegumento do inseto de onde saem as cerdas. As demais características são semelhantes às do estádio anterior. Esse estádio teve duração de 5,55 \pm 0,15 dias, com as lagartas de $M$. amilia apresentando comprimento de 10,42 \pm 0,30 $\mathrm{mm}$ (Quadro 1).

As lagartas de terceiro estádio de $M$. amilia são semelhantes às do anterior, porém apresentam, no segmento anal, duas manchas pretas mais nítidas e de forma triangular. Os espiráculos são brancos, elípticos e com peritrema preto. A duração desse estádio foi de 5,31 $\pm 0,10$ dias, com as lagartas apresentando comprimento de 15,76 $\pm 0,14 \mathrm{~mm}$ (Quadro 1).

A cabeça e o corpo da lagarta de quarto estádio de $M$. amilia são de coloração preta, de forma semelhante à dos demais estádios, porém com cerdas alaranjadas e extremidades brancas. Os espiráculos são alaranjados, com peritrema preto, e mais visíveis

R. Árvore, Viçosa-MG, v.29, n.2, p.321-326, 2005 
que no estádio anterior. As lagartas desse lepidóptero tiveram, nesse estádio, duração de 6,00 \pm 0,02 dias e apresentaram comprimento de 21,00 $\pm 0,21 \mathrm{~mm}$ (Quadro 1). Nesse estádio, a lagarta quando molestada, libera uma secreção verde-escura pela boca.

O corpo e a cabeça de lagartas de quinto estádio de $M$. amilia são pretos e mais escuros que nos estádios anteriores, não sendo possível diferenciar, com nitidez, as pintas pretas e as duas manchas no final do abdome. As demais características são semelhantes às dos estádios anteriores. A duração desse estádio foi de $13,20 \pm 0,16$ dias, com as lagartas apresentando comprimento de 26,72 \pm 0,26 mm (Quadro 1).

\subsection{Pré-pupa e pupa}

As fases de pré-pupa e de pupa de M. amilia ocorrem no casulo confeccionado pela lagarta de último estádio (Figura 1A). Na fase de pré-pupa, a lagarta diminui de tamanho e se mantém imóvel no interior do casulo. Essa fase teve duração de 4,33 \pm 0,33 e 3,90 $\pm 0,23$ dias para machos e fêmeas, respectivamente.

A pupa de $M$. amilia apresenta coloração preta na região dorsal (cabeça e tórax) e avermelhada no abdome, com dois espinhos pretos visíveis e semelhantes a uma mandíbula, voltados para frente na região anterior. Apresenta, ainda, uma fileira de pequenos espinhos nos dois últimos segmentos.

Na região dorsal anterior, as tecas alares das pupas de $M$. amilia apresentam linhas elevadas, e o contorno das asas, dos olhos compostos e das antenas é visível. Na região pleural, a pupa apresenta oito espiráculos visíveis e na parte ventral, o contorno das patas. A duração da fase de pupa foi de 18,78 $\pm 0,69$ e 18,82 $\pm 0,41$ dias em machos e fêmeas, respectivamente. Nessa fase, a pupa está envolta por um casulo bastante resistente com folhas de eucalipto (Figura 2A) ou de goiabeira, como encontrado em Viçosa, Minas Gerais (Figura 2B).

\subsection{Fase adulta}

Machos e fêmeas de $M$. amilia apresentam coloração e envergadura semelhantes, e o dimorfismo sexual dessa espécie é mais acentuado pelo formato das asas (Figura 1B), diferentemente de lepidópteros que apresentam dimorfismo sexual nas antenas (SANTOS et al., 1982; SANTOS et al., 1998; ZANUNCIO et al., 1998). Suas fêmeas possuem asas mais largas com bordas arredondadas, envergadura de 49,7 $\pm 0,17 \mathrm{~mm}$ e abdome piloso de cor preta e mais volumoso, enquanto nos machos as asas são menores, mais estreitas e com bordas irregulares, envergadura de 42,7 $\pm 0,32 \mathrm{~mm}$ e abdome mais fino, com coloração cinza. Fêmeas e machos de M. amilia apresentam asas de coloração cinza semelhante à de indivíduos dessa espécie coletada em cultivo de M. dubia (RIBEIRO et al., 2002). As asas anteriores e posteriores de $M$. amilia apresentam, na região dorsal, duas linhas estreitas regulares, uma preta e outra cinza, e uma grande mancha circular cinza e preta com um orifício central. As laterais das asas são cinzas, com contorno preto.

Mimallo amilia apresenta hábitos peculiares, pois sua lagarta permanece protegida, dentro de um abrigo desde o primeiro estádio, o que dificulta sua visualização no campo, sendo necessário localizar-se esse abrigo para encontrá-la. Durante os três primeiros estádios, esse abrigo é ainda relativamente fraco e está localizado nas folhas de eucalipto ou de goiabeira. Nos últimos é, normalmente, encontrado aderido a galhos finos, podendo também ser visto no tronco do eucalipto e

Quadro 1 - Estádio, número de repetições, duração dos estádios (dias), tamanhos (mm) e razão de aumento da cápsula cefálica e do corpo e mortalidade de lagartas de Mimallo amilia (Lepidoptera: Mimallonidae)

Table 1 - Instar, number of replications, instars duration (days), size ( $\mathrm{mm}$ ) and rate of head capsule incresae and mortality of Mimallo amilia (Lepidoptera: Mimallonidae)'s caterpillars

\begin{tabular}{|c|c|c|c|c|c|c|c|}
\hline \multirow[t]{2}{*}{ Estádio } & \multirow[t]{2}{*}{$\mathrm{N}$} & \multirow[t]{2}{*}{ Duração (dias) } & \multicolumn{2}{|c|}{ Cápsula Cefálica } & \multicolumn{2}{|c|}{ Corpo da lagarta } & \multirow{2}{*}{$\begin{array}{l}\text { Mortalidade (\%) } \\
\text { o } \\
\end{array}$} \\
\hline & & & $\begin{array}{c}\text { Tamanho } \\
(\mathrm{mm})\end{array}$ & $\begin{array}{c}\text { Razão de } \\
\text { Crescimento } \\
\end{array}$ & $\begin{array}{l}\text { Comprimento } \\
\text { Inicial }(\mathrm{mm}) \\
\end{array}$ & $\begin{array}{c}\text { Razão } \\
\text { de Ccrescimento }\end{array}$ & \\
\hline I & 40 & $4,82 \pm 0,06$ & $0,90 \pm 0,01$ & - & $6,49 \pm 0,06$ & - & 5,00 \\
\hline II & 38 & $5,55 \pm 0,15$ & $1,40 \pm 0,02$ & 1,55 & $10,42 \pm 0,30$ & 1,61 & 0,00 \\
\hline II & 38 & $5,31 \pm 0,10$ & $2,11 \pm 0,01$ & 1,51 & $15,76 \pm 0,14$ & 1,51 & 7,89 \\
\hline IV & 35 & $6,00 \pm 0,02$ & $3,10 \pm 0,02$ & 1,47 & $21,00 \pm 021$ & 1,33 & 14,28 \\
\hline $\mathrm{V}$ & 30 & $13,20 \pm 0,16$ & $4,40 \pm 0,03$ & 1,42 & $26,72 \pm 0,26$ & 1,27 & 0,00 \\
\hline
\end{tabular}

R. Árvore, Viçosa-MG, v.29, n.2, p.321-326, 2005 
apresentar resistência muito grande. Por isso, é necessário efetuar-se o monitoramento em eucaliptais para fazer o controle de pragas como $M$. amilia nos estádios iniciais, quando os indivíduos dos lepidópteros desfolhadores são mais suscetíveis.

Adultos de M. amilia foram coletados, principalmente em fevereiro, no Pará, em março e novembro em Minas Gerais e em janeiro em Goiás (ZANUNCIO et al., 1994a), indicando que esse lepidóptero está presente em plantios de eucalipto em várias regiões do Brasil. Desse modo, é importante estudar aspectos biológicos e comportamentais e a caracterização morfológica de $M$. amilia, para se realizar o controle preventivo, quando necessário, desse lepidóptero em plantios de eucalipto. Além disso, a presença de lagartas e de casulos dessa espécie em goiabeira indica que esse, como outros desfolhadores de eucalipto, alimenta-se originalmente de folhas daquela planta. M. amilia é considerada praga secundária em eucaliptais, entretanto possui potencial para se tornar praga primária, pois completa seu ciclo alimentandose de folhas dessa planta, em que outros fatores bióticos ou abióticos controlam a população desse lepidóptero. No entanto, outros estudos são necessários para avaliar o consumo foliar e o crescimento populacional de $M$. amilia em plantios de eucalipto.
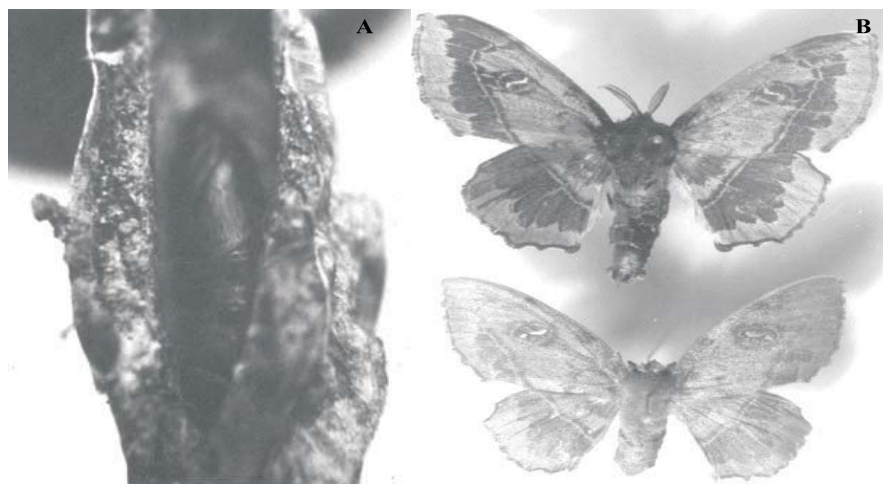

Figura 1 - Pupa e adultos de Mimallo amilia (Lepidoptera: Mimallonidae) coletados em plantas de Eucalyptus urophylla no Município de Montes Claros, Minas Gerais, Brasil. A- Corte do casulo com a pupa e B- Fêmea (superior) e macho (inferior) de Mimallo amilia (Lepidoptera: Mimallonidae).

Figure 1 - Pupae and adults of Mimallo amilia (Lepidoptera: Mimallonidae) collected on Eucalyptus urophylla plants in the Municipality of Montes Claros, Minas Gerais State, Brasil. A-Section of the cocoon with pupae and BFemale (up) e male (down) of Mimallo amilia (Lepidoptera: Mimallonidae).
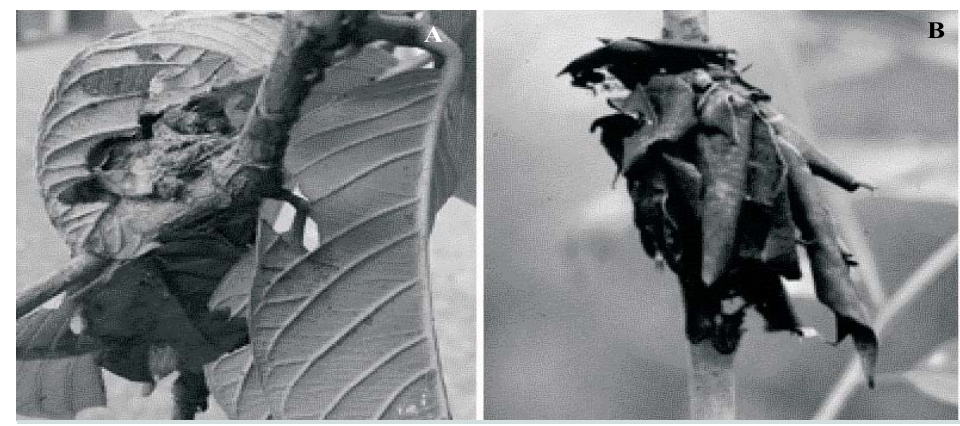

Figura 2 - Casulo de lagartas de Mimallo amilia (Lepidoptera: Mimallonidae). A - Em planta de Psidium guajava no Município de Viçosa, Minas Gerais, Brasil; e B - em planta de Eucalyptus urophylla no Município de Montes Claros, Minas Gerais, Brasil.

Figure 2 - Shelter of Mimallo amilia (Lepidoptera: Mimallonidae. caterpillars. A- on Psidium guajava in the municipality of Viçosa State of Minas Gerais, Brasil and B - on Eucalyptus urophylla in the municipality of Montes Claros,State of Minas Gerais, Brasil. 


\section{AGRADECIMENTOS}

Ao Conselho Nacional de Desenvolvimento Científico e Tecnológico (CNPq), à Coordenação de Aperfeiçoamento de Pessoal de Nível Superior (CAPES) e à Fundação de Amparo à Pesquisa do Estado de Minas Gerais (FAPEMIG), pelo apoio; e ao professor José Eduardo Serrão, da Universidade Federal de Viçosa, pela revisão deste artigo.

\section{REFERÊNCIAS BIBLIOGRÁFICAS}

BERTI FILHO. Biologia de Thyrinteina arnobia (Stoll, 1782) (Lepidoptera: Geometridae) e observações sobre a ocorrência de inimigos naturais. 1974. 74f. Tese (Doutorado em Engenharia Florestal) Escola Superior de Agricultura Luiz de Queiroz, Piracicaba, 1974.

KLIEJUnAS, J.T. et al. Pest risk assessment of the importation into the United States of unprocessed eucalyptus logs and chips from South America. Washington: USDA, 2001. 134f. General Technical Report.

PEREIRA, J.M.M. et al. Lepidoptera pests collected in Eucalyptus urophylla (Myrtaceae) plantations during five years in Três Marias, State of Minas Gerais, Brazil. Revista de Biologia Tropical, v. 49, n. 3-4, p. 1073-1082, 2001.

RIBEIRO, S.I.; MOTA, M.G.C.; CORRÊA, M.L.P. Recomendações para o cultivo do camucamuzeiro no estado do Pará. Belém: EMBRAPA, 2002.9p. (Circular Técnica, 31).

SANTOS, G.P.; ZANUNCIO, J.C.; ANJOS, N. Novos resultados da biologia de Psorocampa denticulata Schaus (Lepidoptera: Notodontidae), desfolhadora de Eucalyptus spp. Revista Árvore, v. 6, n. 2, p. 121-132, 1982.

SANTOS, G.P. et al. Bionomia de Oxydia vesulia (Cramer, 1779) (Lepidoptera: Geometridae), desfolhador de eucalipto. Revista Árvore, v.10, n.2, p. 161-167, 1986.

R. Árvore, Viçosa-MG, v.29, n.2, p.321-326, 2005
SANTOS, G.P. et al. Biologia de Stenalcidia grosica Schaus (Lepidoptera, Geometridae) em folhas de Eucalyptus urophylla e aspectos de sua ocorrência e controle. Revista Brasileira de Entomologia, v. 41, n. 2-4, p. 229-232, 1998.

ZANUNCIO, J.C.; LIMA, J.O.G. Ocorrência de Sarsina violascens (Herrich-Schaeffer, 1856) (Lepidoptera: Lymantriidae) em eucaliptais de Minas Gerais. Brasil Florestal, v. 6, n. 23, p. 48-50, 1975.

ZANUNCIO, J.C. et al. Biologia e consumo foliar de Euselasia apisaon (Dalman, 1823) (Lepidoptera: Riodinidae) em Eucalyptus sp. Revista Árvore, v. 14, n. 1, p. 45-55, 1990.

ZANUNCIO, J.C. et al. Alguns aspectos da biologia de Dirphia rosacordis (Lepidoptera: Saturniidae) em folhas de eucalipto. Revista Árvore, v. 16, n. 1, p. 112-117, 1992a.

ZANUNCIO, J.C et al. Ciclo de vida e consumo foliar de Sarsina violascens (Lepidoptera: Lymantriidae) em Eucalyptus urophylla. Revista Brasileira de Entomologia, v. 36, n. 4, p. 843-850, 1992b.

ZANUNCIO, J.C. et al. Major lepidopterous defoliators of eucalypt in the Southeast Brazil. Forest Ecology and Management, v. 65, n. 1, p. 53-63, 1994a.

ZANUNCIO, T.V. et al. Biologia de Nystalea nyseus (Cramer, 1775) (Lepidoptera: Notodontidae) em folhas de Eucalyptus urophylla. Acta Amazonica, v. 24, n. 1-2, p. 153-160, 1994b.

ZANUNCIO, T.V. et al. Morfologia e bionomia de Thyrinteina leucoceraea Rindge (Lepidoptera: Geometridae) alimentada com Eucalyptus urophylla. Revista Brasileira de Entomologia, v. 41, n. 1, p. 5-8, 1997.

ZANUNCIO, T.V. et al. Aspectos biológicos e morfológicos de Misogada blerura Schaus (Lepidoptera: Notodontidae). Revista Brasileira de Entomologia, v. 41, n. 2-4, p. 527-530, 1998. 